\title{
How Social Media Helps in Time of Crisis in Higher Education
}

\author{
Dr. Worawan Ongkrutraksa \\ Associate Professor, Faculty of Communication Arts, Chulalongkorn University, Thailand
}

\begin{abstract}
The world has been currently effected by the endless crisis such as political conflicts, poverty, environmental problems, natural disasters and terrorists. As a result, the world economy gradually declines and it unavoidably effects a higher education industry. The universities around the world struggle to be in the top of world ranking so they can keep running the businesses and also keep their reputation. The administrators of each universities eagerly fight in order to survive in this fierce ranking competition. Chulalongkorn University, the oldest university and has been ranked as number one in Thailand is not exceptional. The university is trying very hard in every way possible to keep up with the rapidly changing world. However, in this difficult time in Thailand and around the world, the university must develop the beneficial communication policies which can efficiently fit the Thai and the world context especially during a crisis that can happen in any minute. This paper aims to discover how social media can help in time of crisis. It also purposes to support administrators in higher education as a crisis management's guideline. This paper collects the case studies that involved the roles of "social media" such as Facebook in crisis management. The noteworthy crisis cases were collected from public relations (PR) practitioners who had practical involvements and came across each cases from 2008-2016. This paper displays circumstantial situations, what have been the solutions and lesson learned in each cases. The cases also reveal how the university gained "LIKED" in Facebook, how to interact efficiently with the faculties, staffs, students and how to deal with external public such as the press. This paper concludes that the social media such as Facebook is an effective PR tool as it fits well with audiences' behavior in social media environment. However, other traditional PR media such as face to face communication and personal connection are still needed to finally resolve some challenging crisis. In addition, the crisis communication in higher education cannot be perfected without dedicated, committed PR teamwork with genuine faith in their own organization.
\end{abstract}

Keywords: Social Media, Crisis management, Higher education

\section{Introduction}

The world has been currently effected by the endless crisis such as political conflicts, poverty, environmental problems, natural disasters and terrorists. As a result, the world economy gradually declines and it unavoidably effects a higher education industry. The universities around the world struggle to be in the top of world ranking so they can keep running the businesses and also keep their reputation. The administrators of each universities eagerly fight in order to survive in this fierce ranking competition. Chulalongkorn University or "Chula" for short, the oldest university and has been ranked as number one in Thailand is not exceptional. The university is trying very hard in every way possible to keep up with the rapidly changing world. However, in this difficult time in Thailand and around the world, the university must develop the beneficial communication policies which can efficiently fit the Thai and the world context especially during a crisis that can happen in any minute.

Chula, has faced many issues and crisis which require a well-planned communication and strategic public relations management. Not only to set the record straight internationally and domestically but also to elevate university images. Prof. Pirom Kamolratanakul (M.D.), the former president of Chula (during 2008 - 2016) recognized the urge to modernize the traditional image of the university. Chula is now using highly active public relations strategy to reposition its identity and image to both local and international publics.

Thus, in 2011, Chula started using social media intensively mainly for informing the news and important information to students, staffs, press media and external publics both in time of crisis and in normal situation (see figure 1 for numbers of user in different kind of Chula social media as of July 2016). 
This paper aims to discover how social media can help Chula in time of crisis. It also purposes to support administrators in higher education as a crisis management's guideline. This paper collects the case studies that involved the roles of "social media" such as Facebook in crisis management. The noteworthy Chula crisis cases were collected from public relations (PR) practitioners who had practical involvements and came across each cases from 2008-2016.

\section{What is "Social media" for higher education?}

Davis III, Deil-Amen, Rios-Aguilar, \& Canche (2012) stated that:

"Social media is web-based and mobile applications that allow individuals and organizations to create, engage, and share new user-generated or existing content, in digital environments through multi-way communication. Use through computer and mobile devices, currently, the two most prominent interfaces are Facebook and Twitter. HIGHER EDUCATION use for specific purposes (e.g., marketing, recruitment, learning, and/or student engagement)." [1]

\section{How Chula gained LIKED!}

Chula Communication Center (CCC) introduced Chula social media on Chula print, or off line media and keeps Chula social media alive. Always post new, interesting, vital, indispensable content, the audiences will LIKE plus SHARE and comment. Moreover, finding good content from other offices or network and share the links can be advantageous for connecting audiences with beneficial content.

CHULA

$$
\begin{gathered}
\text { Social } \\
\text { Media } \\
\text { (as of July 2016) }
\end{gathered}
$$
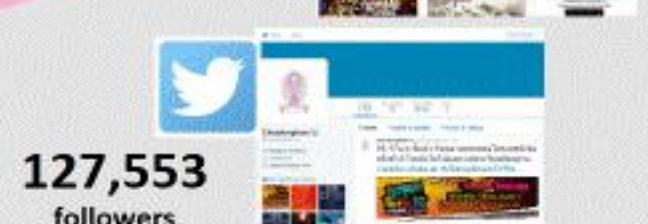

followers

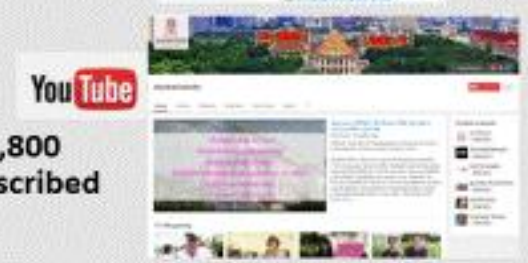

\section{ศูนย์สี่อสารองค์กร จุพาลงกรณ์มหาวิทยาลัย}
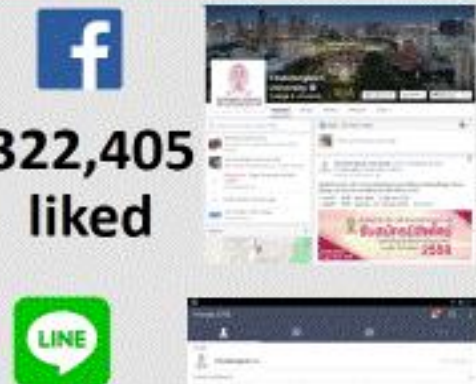

Friends (Non-official Line's max friend $=$ $5,000) 5,000$
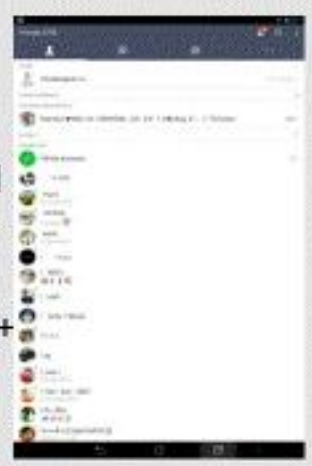

Fig. 1: Numbers of user in different kind of Chula social media.

\section{Who are Chula's SOCIAL media target audiences?}

Mainly GEN X who are always online and mostly exposed to social media only. Since the nature of most social media users are young and have short concentration, all content should be edited to short and easy language plus nice designed cartoons, picture or info graphic. 


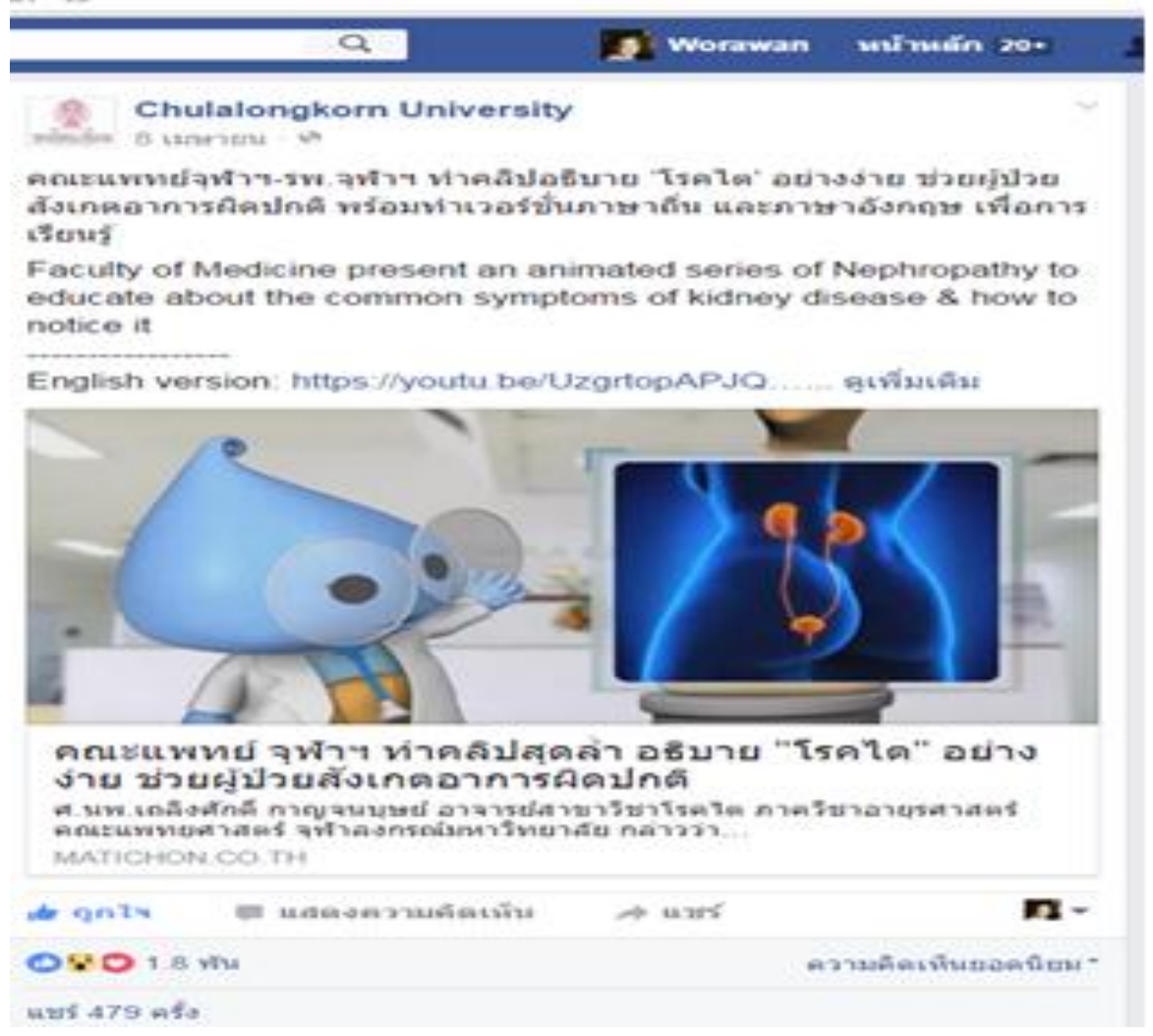

Fig. 2: Example of cartoon used in Chula Facebook.

\section{How to evaluate social media effectiveness.}

1. Do the survey.

2. Find out how many LIKE or followers?

3. Comment monitoring: check how the content were shared to public especially comment/reply and share/repost. It will get personally to individual opinion and this is when we can evaluate if our content has reached its purpose or not

\section{The case studies of social media for issue \& crisis management}

\subsection{Case study 1: big flood in Thailand (2011) [2]}

Situation: A major flood occurred in Thailand, causing heavy flooding in Bangkok. Many residents had to evacuate from their homes because of safety concerns. Mobile kitchen makes over 45,000 fresh meal per day to be distributed to flood victims.

Spokesperson: President, other major administrators

Media Channel: Social Media /TV/ Website / SMS / Hotline

Main Message: Chula would serve as a temporary relief shelter and recruited volunteers to help victims in designated areas.

Lesson learned: Lot of LIKED (number of people who are following Chula Facebook) just came naturally if the public need critical information. During big flood or political crisis, students and staffs always need information about university open or close dates, etc. Therefore, keep the social media alive and have a quick reaction on the difficult questions 


\subsection{Case study 2: stray dog in campus (2011)}

Situation: Rumors surfaced that the Faculty of Pharmaceutical Sciences caged stray dogs within a building construction site. The general public was outraged against this alleged act of mistreatment.

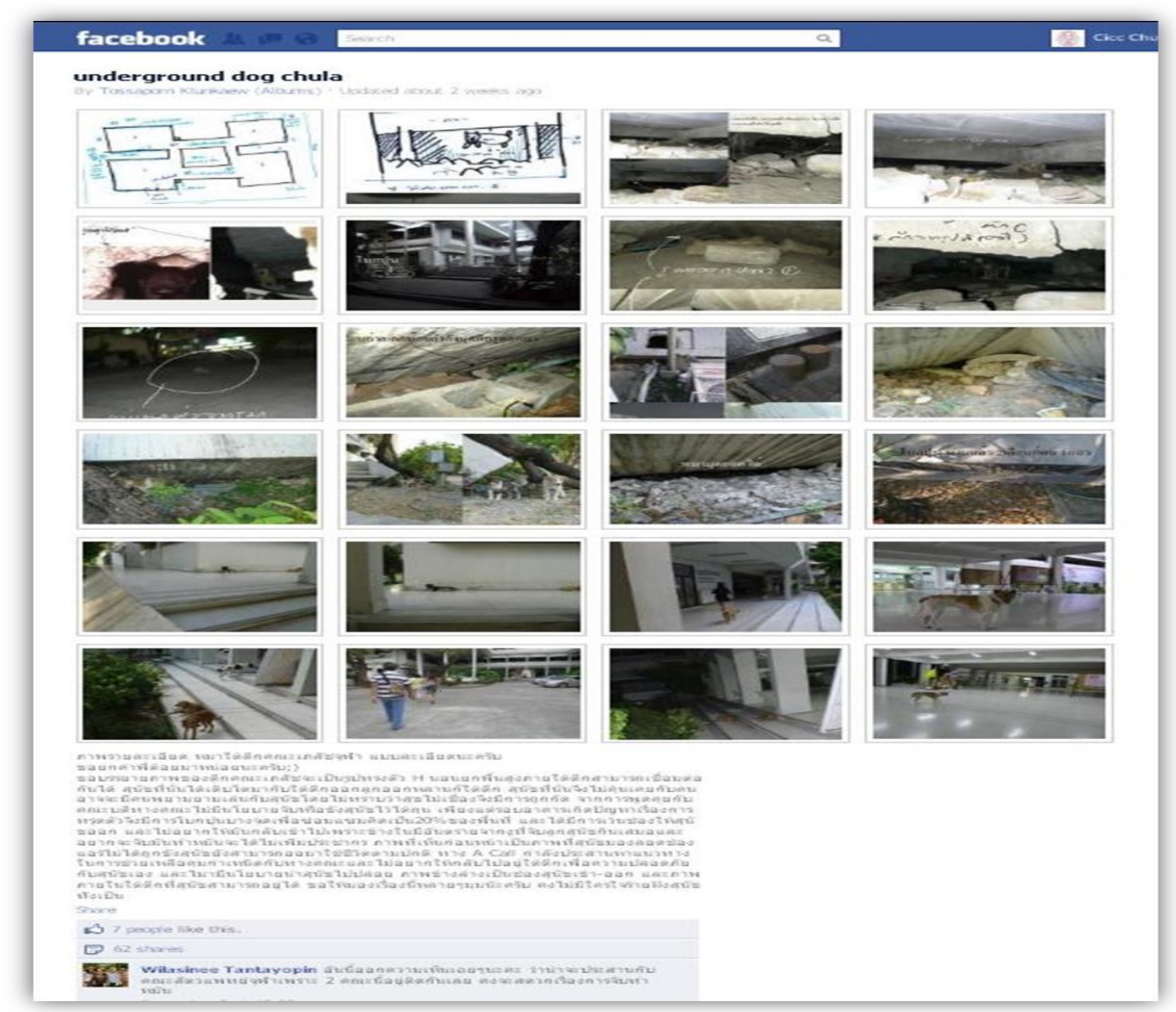

Fig. 3: Pictures of caged stray dogs on Facebook.

Spokesperson: Dean of Faculty of Pharmaceutical Sciences

\section{Media channel: Social Media/ Press Release / Press Tour}

Message: The faculty stated that no such incident had occurred by inviting reporters and external foundation representatives to investigate the site. The faculty further explained renovations included plastering walls. So, a small hole had been cut so dogs in the site could escape. Chula reassured the public that it took safety control measures to reduce the number of stray dogs on campus by working with external foundations.

Result: The truth disseminated among the general public. Animal lover groups were informed and in turn helped spread the news for clarity. Chula re-earned public trust and was commended for its quick action.

Lesson learned: "Loss of control" easily happens in the social media context. The traditional media such as TV and newspapers usually pick up the hot and critical issues from critical comments that a lot of people pay attention to on social media. Once the issue goes on the main stream media, it starts to get out of control. A perfect example of the loss of control relates to blogs and their "comments" feature. This feature can easily be turned off, but then that begs the question - why even use the blog format to begin with? [3] .Therefore, always set up the team to monitor the comments on social media that might have potential to create an issue. If there is any challenging and critical comments, the team must consult with the upper administrator as soon as possible. 


\subsection{Case Study 3: Ratchaprasong Bombing (2015)}

Situation: A bombing occurred near to the Ratchaprasong intersection, which is close to Chula campus, causing fatalities and injuries. The government declared a State of Emergency.

Spokesperson: Vice President for Physical Resources Management

Media channel: Social Media /Press Release / Website / SMS / Hotline

Message: Chula announced the cancellation of classes and closure of the campus due to safety concerns. Chula initiated higher security measures. Hotlines were established to keep students, faculty, staff and the general public up-to-date with announcements and actions.

Result: Danger was reduced for students, faculty and staff. Hotlines issued news and established hotlines to keep students, faculty, staff and the general public up-to-date with announcements and actions.

Lesson learned: Other traditional PR media such as Hotlines and personal connection are still needed to finally resolve some challenging crisis outside the campus. In addition, under the unstable political climate in and outside Thailand, any emergency incident can occur anytime, thus a dedicated, committed PR teamwork with genuine faith in their own organization are indispensable since the crisis needs an intensive attention at all time.

\section{Conclusion}

This paper displays circumstantial situations, what have been the solutions and lesson learned in each cases. The cases also reveal how the university gained "LIKED" in Facebook, how to interact efficiently with the faculties, staffs, students and how to deal with external public such as the press. This paper concludes that the social media such as Facebook is an effective PR tool as it fits well with audiences' behaviour in social media environment. However, other traditional PR media such as Hotlines and personal connection are still needed to finally resolve some challenging crisis outside campus. In addition, the crisis communication in higher education cannot be perfected without dedicated, committed PR teamwork with genuine faith in their own organization.

\section{Acknowledgements}

Thanks Chula communication center (CCC) and Mr.Phruet Promwong for information provided in this paper.

\section{References}

[1] DAVIS III, Charles HF, et al. Social Media in Higher Education: A literature review and research directions. 2012.

[2] W. Ongkrutraksa, "The use of social media for issues in higher education," presented at the 7th TCU International elearning Conference 2016, Bangkok, Thailand July 28-29, 2016.

[3] REUBEN, Rachel. The use of social media in higher education for marketing and communications: A guide for professionals in higher education. 2008. 